\title{
Effect of Nursing Staff Development Regarding Ureteral Stent Management on Nurses' Knowledge and Practice
}

\author{
Amina Ibrahim Badawy ${ }^{*}$, Neima Ali Riad, Manal Elsayed Fareed \\ Medical Surgical Nursing, Faculty of Nursing, Menofia University, Shebin El-Koom, Egypt \\ Email address: \\ amina73737373@yahoo.com (A. I. Badawy) \\ ${ }^{*}$ Corresponding author \\ To cite this article: \\ Amina Ibrahim Badawy, Neima Ali Riad, Manal Elsayed Fareed. Effect of Nursing Staff Development Regarding Ureteral Stent \\ Management on Nurses' Knowledge and Practice. American Journal of Nursing Science. Vol. 8, No. 6, 2019, pp. 317-323. \\ doi: 10.11648/j.ajns.20190806.15
}

Received: September 25, 2019; Accepted: October 14, 2019; Published: October 26, 2019

\begin{abstract}
Ureteral stent is a hollow tube with multiple side holes that is used widely by the urologists in many urological procedures. This study was carried out to determine the effect of nursing Staff development regarding ureteral stent management on nurses' knowledge and practice. A quasi-experimental research design was utilized to achieve the aim of the study. A design of one group pre/post test was used. This study was conducted in urological department of university Hospital in Menoufiya. A purposive sample of 70 nurses were selected. These nurses provided care for patients admitted to the urological department in the previously mentioned setting. I- Structured Interviewing Questionnaire: II- and An Observational Checklist. Study findings shows that none of the nurses in the study sample had satisfactory total knowledge and practice at the pre-program implementation. Although few of them had satisfactory knowledge regarding some aspect, the majority had unsatisfactory knowledge regarding ureteral stent management, patient's teaching and stent removal which shows that there is a need of educational programmes in order to improve their knowledge level. The score of total knowledge and practice were significantly increased immediately after the program, and continued to be higher at the follow-up period, this may indicate that, educational programme leads to gain knowledge, and improve practice which might have an impact on improvement of ureteral stent management. The current study shows that none of the nurses in the study sample had satisfactory total knowledge at the pre-program implementation, indicating that the respondents lacked knowledge. However, the score of total knowledge increased immediately after the program, and continued to be higher at the follow-up phase, indicating that the nurses gained knowledge after the teaching program which was implemented. On the other hand, it was observed that there was an association between age, years of experience, and knowledge, and practice of nurses regarding uretral stent management. As well, age, years of experience, and education were found to have an impact on knowledge scores. Nurses should take initiative to improve their knowledge and practices by using online education, virtual learning, booklets, posters, brochures, charts etc.
\end{abstract}

Keywords: Ureteral Stent, Staff Development, Knowledge, Practice

\section{Introduction}

Ureteral stent is a hollow tube with multiple side holes that is used widely by the urologists in many urological procedures such as relieving ureteral stricture or obstruction related to cancer or renal calculi, reducing pain that is experienced with kidney stones, facilitating drainage in the presence of infection and facilitating flow of urine from the kidney to the bladder [1]. Stents are also commonly used after removal of calculi, as in ureteroscopy to facilitate healing and prevent swelling of the ureter [2-3]. Ureteral stent placement is associated with some degree of morbidity in the majority of patients that ranges from generalized urinary discomfort to urinary tract infection or obstruction $[1]$.

A myriad of stent designs is available with various stent materials, coating, size, and shape. The stent designs are aimed at improving patient's comfort, handling of stent and reducing the incidence of urinary tract infection and 
encrustation [1, 4]. It is inserted with cystoscopic guidance in the operating room since fluoroscopy is needed to verify accurate placement. The stent is inserted by using a soft guidewire which is introduced up the ureter [2, 4, 5]. It shouldn't remain more than 3 months, when it is left more than this period; the removal of the stent will be difficult because of developing a stone directly on it [2].

Stents can be removed within two to three days after ureteroscopy in uncomplicated cases or they can be removed after one to two weeks in cases of ureteral perforation or persistence of obstruction. The removal occurs in two different ways either in outpatient clinics with topical anesthesia with a flexible ureteroscope and grasper where the string is pulled out gently from the patient's urethra to facilitate the stent removal or it can be removed in the operating room under general anesthesia for patients who are unable to tolerate topical anesthesia. If a string is not present, a cystoscope is introduced into the patient's urethra, then advanced into the bladder and the stent can be removed easily [4, 6, 7].

The main complications associated with ureteral stent placement can be ranged from minor discomfort to severe complications such as urgency, hematuria, bladder spasms, dysuria, back pain with urination or during ambulation and bladder pain $[4,7]$. Also it can lead to urinary tract infection, stent migration within the urinary tract, stent encrustation and retained stents. Rare complications include stent migration out of the urinary tract, such as into the inferior vena cava and reflux anuria following removal of bilateral prophylactic ureteral stents or obstruction and potential loss of kidney function $[8,9]$.

Patients should be instructed that ureteral stents are temporary devices that need to be changed regularly and are removed when no longer needed; as well they should be instructed about ureteral stents potential complications and how to manage [10].

The renal nurse needs to support and assist the patient and their relatives to cope with Ureteral Stent in the best way possible and to manage its care. Nurses caring for these patients require specialist knowledge to reduce problems by prevention or anticipation and early intervention to maximize short- and long-term outcome. Patients (and relatives) who are engaged with the process are better equipped to care for themselves and this also contributes to the success of Ureteral Stent. Therefore, this study was conducted to determine the effect of nursing staff development regarding ureteral stent management on nurses' knowledge and practice.

\subsection{Significance of the Study}

Research priorities emphasized global concerns of healthcare related to patients' safety, infection control and preventing potential complications related to devices such as urinary catheters and ureteral stents $[11,12]$.

This study will provide a base of knowledge for nurses on ureteral stent management, and ensure the highest standards of nursing management that is aiming at improving patients' outcomes. It is hoped that this effort might help nurses to improve their practice in assessment, planning, implementation and evaluation of such patients. This will reflect on shortening patient's length of stay, as well as decreasing hospital costs.

In addition, it might generate an attention and motivation for further researches into this area.

\subsection{Aim of the Study}

This study was carried out to determine the effect of nursing Staff development regarding ureteral stent management on nurses' knowledge and practice.

\subsection{Research Hypotheses}

The following research hypotheses were formulated in an attempt to achieve the aim of the study:

1. The mean total knowledge score of nurses about ureteral stent management post intervention is higher than pre intervention.

2. The mean total practice score of nurses regarding ureteral stent management post intervention is improved than pre intervention.

3. There will be a correlation between nurses' age, level of education and years of experience with their knowledge and practice scores regarding ureteral stent management.

\section{Subjects and Method}

\subsection{Subjects}

\subsubsection{Study Variables}

The independent variable in this study was the development provided for the nurses on ureteral stent management, while the dependent variables were the nurses knowledge and practice

\subsubsection{Design}

A quasi-experimental research design was utilized to achieve the aim of the study. A design of one group pre/post test was used.

\subsubsection{Setting}

This study was conducted in urological department of university Hospital in Menoufiya.

\subsubsection{Subjects}

Purposive samples of 70 nurses were selected. These nurses provided care for patients admitted to the urological department in the previously mentioned setting.

\subsubsection{Exclusion Criteria}

Nurses were excluded from the study if they:

1. Have already attended formal teaching programme on ureteral stent management.

2. Not willing to participate in the study.

3 . Were in vacations.

\subsection{Instrumentation}

\subsubsection{Structured Interviewing Questionnaire}

It was designed by the researchers to assess nurse's 
knowledge about ureteral stent management; it consists of two main parts:

A. Part one: It included information about demographic data such as age, level of education, and years of experience.

B. Part two: It includes 48 multiple choice questions regarding knowledge about ureteral stent management.

It covered the following sections:

Section-A: Consisted of 9 questions regarding general information about ureteral stent.

Section-B: Consists of 10 questions on ureteral stent complications.

Section-C: Consists of 7 questions regarding nursing care for patients with ureteral stent.

Section-D: Consists of 12 questions regarding patient's teaching about ureteral stent management.

Section-E: Consists of 10 questions regarding Stent removal.

Scoring system:

Each question was given a score of one if the answer is correct, and 'zero' for wrong answer with overall scores of 48. Less than $85 \%$ is considered as having an unsatisfactory knowledge level.

\subsubsection{An Observational Checklist}

This checklist was developed by the researchers to assess nurses' practice for stent care, it includes 16 statement to be checked by the researchers.

Scoring system:

Each statement was given a score of two for each correct complete action, one for correct incomplete action, and zero for incorrect action, with total scores of 32 . Less than (85\%) is considered an unsatisfactory practice level.

\subsubsection{Teaching Program for Ureteral Stent Management}

i. General Objectives: Upon completion of this teaching program, the nurse will gain knowledge regarding ureteral stent management.

ii. Specific Objectives

Upon completion of this teaching program, the nurse will be able to:

i.) Define ureteral stent.

ii.) Describe ureteral stent complications.

iii.)Describe nursing care.

iv.)List patient teaching.

iii.Contents

Theoretical contents: Topics introduced: General information about ureteral stent, ureteral stent complications, nursing care, patient teaching, and stent removal.

Timing: introduced through two weeks (2 sessions /week for each group) 20 minutes for each session so the contents given in 80 minutes through 4 sessions.

The practical contents: stent care.

Timing: introduced through one-week ( 1 session /week for each group) half hour per the session, so, the practical contents given in 30 minutes.

Date: the program begins at 15-1-2018 and ends at 15-32018.
Teaching methods: lecture, small group discussion, demonstration, and re-demonstration.

Audiovisual aids: PowerPoint slides, illustrated charts, illustrated Arabic booklet.

Model: For demonstration, and re-demonstration of stent care.

Evaluation: formative (quizzes and Asking questions) and summative (post test).

\subsection{Method}

\subsubsection{Approval to Conduct the Study}

An official written letter was issued to the director of the university hospital Prior to data collection, after explaining the aim of the study.

\subsubsection{Protection of the Human Rights}

Each nurse was informed about the purpose, and the nature of the study and your participation is totally voluntary and the confidentiality and anonymity were assured

\subsubsection{Period of the Study}

Data collection was extended over a period of 6 months at 1-1-2018 to 30-6-2018.

\subsubsection{Tools Validity}

The tools were tested for content validity from tow experts in medical surgical nursing to ascertain relevance, and competence, and reliability were tested using a test retest method which revealed that, all items were significant and has a correlation coefficient above the significance level ( $\mathrm{r}=0.79$ for the first tool $\& 0.89$ for the second tool). A pilot study was carried out before starting data collection on $10 \%$ of the sample ( 7 nurses), to evaluate the tentative developed tools for clarity and applicability, as well as to estimate the time needed for data collection. Needed modifications were carried out accordingly.

\subsubsection{Procedure}

The study was conducted in four consecutive phases. These phases were as follow:

\section{i. Assessment Phase}

The first interview was carried out to collect base line data for all studied nurses by using the first structured tool (structured interviewing questionnaire) such as demographic and subjects' knowledge about stent management. Then all studied nurses were observed for their performance during their work with ureteral stent patients by using the second tool (observational checklist).

ii. Planning Phase

Based on assessment phase and extensive literature review, educational needs were identified. The designed program was prepared in a colored booklet.

iii.Implementation Phase

For theoretical contents: based on nurses' roster, they were divided into small groups:

Group A (25 nurses) was divided into 5 groups

Group B (24 nurses) was divided into 5 groups 


\section{Group C (21 nurses) divided into 4 groups}

The teaching sessions were scheduled according to nurses' work involvement, short interactive teaching sessions of lectures and group discussion that was supported by audiovisual aids such as colored pictures were conducted for each group. Each session lasted 20 minutes. The number of sessions for each group was 4 , which were given in two weeks. Moreover, the designed booklet was distributed by the researchers for each studied nurse.

For the practical part, demonstration and redemonstrations on a model was used. The practical session was one for each group. The session was lasted for 30 minutes.

Continuous feedback was assured to clear any misconception or misunderstanding, as well as to reinforce the learned knowledge and practice.

1. The researcher was available for 3 days/week at wards.

2. Nurses were evaluated 3 times after the pre-assessment. The first assessment was immediately after implementation of the structured teaching program (post test). The second was on the $2^{\text {nd }}$ week and the last assessment was after 4 weeks from the immediate post test.

iv. Evaluation Phase

All nurses were evaluated three times after assessment. The first evaluation session was immediately after implementing the designed teaching (immediate post test). The second evaluation was on the $2^{\text {nd }}$. Week and the last one was after four weeks from the immediate post test. These evaluations were carried out utilizing the first and second tools, and then a comparison between assessment data and data of three evaluation sessions was carried out to determine the effect of the designed teaching module about ureteral stent management on nurse's knowledge and practice.

\section{Statistical Analysis}

The data was tabulated and analyzed by using SPSS program (statistical package for social science software) version 18.

Quantitative data was expressed as mean and standard deviation $(\mathrm{X} \pm \mathrm{SD}) \mathrm{A}$ qualitative data was expressed in numbers and percentage $(\mathrm{N}, \%)$, Pearson correlation analysis were used for identifying the relationships among quantitative variables, and one-way ANOVA. Statistical significance was started at $\mathrm{p}$-value $<0.05$.

\section{Results}

Table 1 shows that about half of studied nurses (51.4\%) were in the age group from twenty-six to thirty years with a mean age of $29.32 \pm 6.7$ years. Concerning years of experience, less than half of studied nurses $(45.7 \%)$ had less than six years of experience, while $37.2 \%$ had more than 10 years. With respect to professional educational qualification, it was observed that minority of them (12.9\%) had Bachelorette degree in nursing and $87.1 \%$ had Nursing diploma.

Table 2 reveals that pre teaching program, none of studied nurses $(0 \%)$ had satisfactory total knowledge score however, post teaching, the majority of studied nurses (95.7\%, 94.2\% and 95.7\%) during the three evaluation sessions respectively had satisfactory total knowledge score.

Figure 1 show that means total knowledge score of studied sample was $9.04 \pm 6.52$ Pre teaching program. However the mean score of total knowledge increased immediately after the teaching program and continued to be high at the next evaluation sessions (46.92 \pm 11.46 , $46.82 \pm 10.4$ and $46.72 \pm 11.26$ respectively) (statistically significant, $\mathrm{p}<0.001)$.

Table 3 reveals that pre teaching program, non of studied nurses $(0 \%)$ had satisfactory total practice score, however, post teaching, the majority of studied nurses $(92.9 \%, 94.2 \%$ and $95.7 \%$ ) during all evaluation sessions respectively had satisfactory total practice score.

Figure 2 shows that mean total score of studied sample was $6.40 \pm 6.52$.

Pre teaching program. However the mean score of total practice increased immediately after the teaching program and continued to be high at the following evaluation sessions $(30.79 \pm 10.22,31.09 \pm 10.00$ and $30.99 \pm 9.90$ respectively) (statistically significant, $\mathrm{p}<0.001$ ).

Table 4 reveals that nurses who were more than 30 years had significantly the greatest mean total knowledge score $(47.90+10.32)$ (statistically significant, $\mathrm{p}<0.05)$.

Table 5 illustrates that, the more experienced the nurses, the significance greater mean total knowledge score they had $(47.94+11.32)$ (statistically significant, $\mathrm{p}<0.05)$.

Table 6 shows that, Nurses who had Bachelorette degree in Nursing, had more mean total knowledge score $(47.92+12.01)$ than who had Nursing Diploma $(44.79+10.00)$ (statistically significant, $\mathrm{p}<0.05$ ).

Table 7 shows that there is a strong positive correlation was found among age, experience, knowledge and practice for nurses.

Table 1. Distribution of demographic characteristics of the Studied Nurse.

\begin{tabular}{|c|c|c|}
\hline \multirow{2}{*}{ Demographic characteristics } & \multicolumn{2}{|c|}{ Studied Nurses $N=70$} \\
\hline & No & $\%$ \\
\hline \multicolumn{3}{|l|}{ Age (years) } \\
\hline $21-$ & 24 & 34.2 \\
\hline $26-$ & 36 & 51.4 \\
\hline More than 30 & 10 & 14.4 \\
\hline $\mathrm{X} \pm \mathrm{SD}$ & 29.3 & \\
\hline \multicolumn{3}{|l|}{ Years of experience } \\
\hline $1-$ & 32 & 45.7 \\
\hline $6-$ & 12 & 17.1 \\
\hline More than 10 years & 26 & 37.2 \\
\hline $\mathrm{X} \pm \mathrm{SD}$ & & \\
\hline \multicolumn{3}{|l|}{ Levels of education } \\
\hline Nursing diploma & 61 & 87.1 \\
\hline Bachelorette degree & 9 & 12.9 \\
\hline
\end{tabular}


Table 2. Distribution of total and subtotal knowledge scores among studied Nurses pre and post teaching.

\begin{tabular}{|c|c|c|c|c|c|c|c|c|c|}
\hline \multirow{2}{*}{$\begin{array}{l}\text { Knowledge } \\
\text { items }\end{array}$} & \multicolumn{2}{|c|}{$\begin{array}{l}\text { Pre teaching } \\
\mathrm{N}=70\end{array}$} & \multicolumn{2}{|c|}{$\begin{array}{l}\text { Immediate post teaching } \\
\mathrm{N}=70\end{array}$} & \multicolumn{2}{|c|}{$\begin{array}{l}\text { Two weeks post teaching } \\
\mathrm{N}=\mathbf{7 0}\end{array}$} & \multicolumn{2}{|c|}{$\begin{array}{l}\text { Four weeks post teaching } \\
\mathrm{N}=70\end{array}$} & \multirow{2}{*}{$\begin{array}{l}\text { ANOVA } \\
\text { (F)/p values }\end{array}$} \\
\hline & $\%$ & No & $\%$ & No & $\%$ & No & $\%$ & No & \\
\hline \multicolumn{10}{|c|}{ General Information about ureteral stent } \\
\hline Satisfactory & 7.1 & 5 & 94.2 & 66 & 92.9 & 65 & 92.9 & 65 & \\
\hline Unsatisfactory & 92.9 & 65 & 5.8 & 4 & 7.1 & 5 & 7.1 & 5 & $\mathrm{~F}=120.40 * * *$ \\
\hline Mean \pm SD & $2.50 \pm 1.1$ & & $7.95 \pm 2.6$ & & $7.95 \pm 2.4$ & & $7.65 \pm 2.3$ & & \\
\hline \multicolumn{10}{|c|}{ Ureteral stent complications } \\
\hline Satisfactory & 5.8 & 4 & 92.9 & 65 & 94.2 & 66 & 92.9 & 65 & \\
\hline Unsatisfactory & 94.2 & 66 & 7.1 & 5 & 5.8 & 4 & 7.1 & 5 & $20.43^{* *}$ \\
\hline \multicolumn{9}{|l|}{ Nursing care } & \\
\hline Satisfactory & 15.7 & 11 & 97.2 & 68 & 97.2 & 68 & 97.2 & 68 & \\
\hline Unsatisfactory & 84.3 & 59 & 2.8 & 2 & 2.8 & 2 & 2.8 & 2 & $60.99 * * *$ \\
\hline $\begin{array}{l}\text { Mean } \pm \text { SD } \\
\text { patient teaching }\end{array}$ & $1.94 \pm 1.2$ & & $6.96 \pm 2.5$ & & $6.86 \pm 2.4$ & & $6.56 \pm 2.3$ & & \\
\hline Satisfactory & 5.8 & 4 & 97.2 & 68 & 97.2 & 68 & 95.7 & 67 & \\
\hline Unsatisfactory & 94.2 & 66 & 2.8 & 2 & 2.8 & 2 & 4.3 & 3 & $110.40^{* * *}$ \\
\hline Mean \pm SD & $1.90 \pm 1.6$ & & $5.56 \pm 2.6$ & & $5.44 \pm 2.5$ & & $5.45 \pm 2.4$ & & \\
\hline \multicolumn{10}{|l|}{ Stent removal } \\
\hline Satisfactory & 0 & 0 & 95.7 & 67 & 94.2 & 66 & 95.7 & 67 & $64.44 * * *$ \\
\hline Unsatisfactory & 100 & 70 & 4.3 & 3 & 5.8 & 4 & 4.3 & 3 & 64.44 \\
\hline Mean \pm SD & $1.60 \pm 3.9$ & & $8.75 \pm 5.3$ & & $8.65 \pm 5.1$ & & $8.55 \pm 5.3$ & & \\
\hline \multicolumn{10}{|c|}{ Total knowledge score } \\
\hline Satisfactory & 0 & 0 & 95.7 & 67 & 94.2 & 66 & 95.7 & 67 & \\
\hline Unsatisfactory & 100 & 70 & 4.3 & 3 & 5.8 & 4 & 4.3 & 3 & $115.0^{* * *}$ \\
\hline Mean \pm SD & $9.04 \pm 6.52$ & & $46.92 \pm 11.46$ & & $46.82 \pm 10.40$ & & $46.72 \pm 11.26$ & & \\
\hline
\end{tabular}

**Significant at $0.01 * * *$ Significant at 0.001

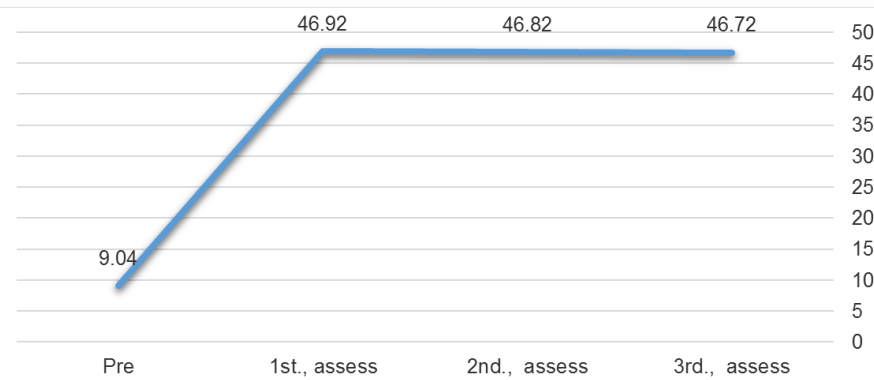

Figure 1. Differences of mean total knowledge scores among studied Nurses pre and post teaching program (Total $n=70)$.

Table 3. Distribution of total practice scores among studied Nurses pre and post teaching.

\begin{tabular}{|c|c|c|c|c|c|c|c|c|c|}
\hline \multirow[t]{2}{*}{ Total Practice score (36) } & \multicolumn{2}{|c|}{$\begin{array}{l}\text { Pre teaching } \\
\mathrm{N}=70\end{array}$} & \multicolumn{2}{|c|}{$\begin{array}{l}\text { Immediately post } \\
\text { teaching } N=70\end{array}$} & \multicolumn{2}{|c|}{$\begin{array}{l}\text { Two weeks post } \\
\text { teaching } N=70\end{array}$} & \multicolumn{2}{|c|}{$\begin{array}{l}\text { Four weeks post } \\
\text { teaching } N=70\end{array}$} & \multirow[t]{2}{*}{ F - p values } \\
\hline & No & $\%$ & No & $\%$ & No & $\%$ & No & $\%$ & \\
\hline Satisfactory $(85 \%+)$ & 0 & 0 & 65 & 92.9 & 66 & 94.2 & 67 & 95.7 & $\mathrm{~F}=$ \\
\hline Unsatisfactory $<(85 \%)$ & 70 & 100 & 5 & 7.1 & 4 & 5.8 & 3 & 4.3 & $109.00 * * *$ \\
\hline Mean \pm SD & \multicolumn{2}{|c|}{$6.40 \pm 6.52$} & \multicolumn{2}{|c|}{$30.79 \pm 10.22$} & \multicolumn{2}{|c|}{$31.09 \pm 10.00$} & \multicolumn{2}{|c|}{$30.99 \pm 9.90$} & \\
\hline
\end{tabular}

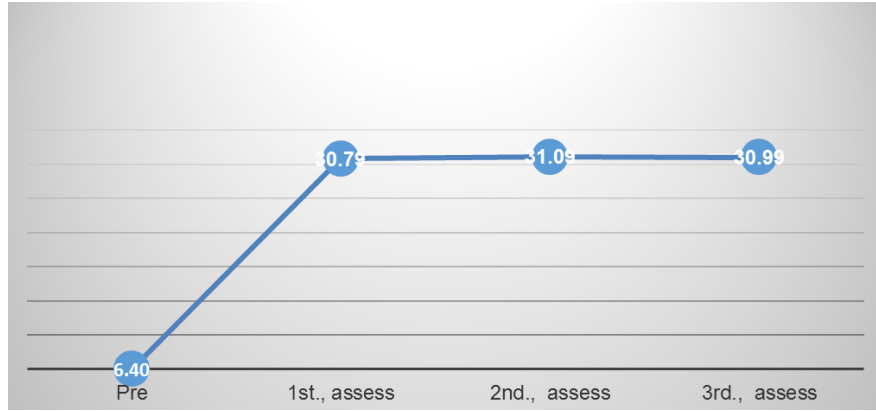

Figure 2. Differences of mean total practice scores among studied Nurses pre and post teaching program (Total $n=70$ ). 
Table 4. Relation between means total knowledge scores of studied Nurses with their ag $n=70$.

\begin{tabular}{llll}
\hline \multirow{2}{*}{ Item } & $\mathbf{2 1}-$ & $\mathbf{2 6}-$ & $>\mathbf{3 0}$ \\
\cline { 2 - 4 } & Mean \pm SD & Mean \pm SD & Mean \pm SD \\
\hline Mean total knowledge score & $42.77 \pm 10.00$ & $45.90 \pm 10.00$ & $47.90 \pm 10.32$ \\
\hline
\end{tabular}

Table 5. Relation between mean total knowledge scores of studied Nurses with their years of experience $n=70$.

\begin{tabular}{llll}
\hline \multirow{2}{*}{ Item } & $\mathbf{5 - 1 0}$ years & $\mathbf{1 0}-\mathbf{1 5}$ years & $>\mathbf{1 5}$ \\
\cline { 2 - 4 } & Mean \pm SD & Mean \pm SD & Mean \pm SD \\
\hline Mean total knowledge score & $45.72 \pm 10.01$ & $47.92 \pm 12.00$ & $47.94 \pm 11.32$ \\
\hline
\end{tabular}

Table 6. Relation between mean total knowledge scores of studied Nurses with their level of education $n=70$.

\begin{tabular}{lll}
\hline \multirow{2}{*}{ Item } & Nursing Diploma & Bachelorette degree in Nursing \\
\cline { 2 - 3 } & Mean \pm SD & Mean \pm SD \\
\hline Mean total Knowledge score & $44.79 \pm 10.00$ & $47.92 \pm 12.01$ \\
\hline
\end{tabular}

Table 7. Correlation matrix of age, experience, knowledge and Practice of studied Nurses $n=70$.

\begin{tabular}{llll}
\hline Item & Age & Experience & Knowledge \\
\hline Age & 1.00 & & Practice \\
Experience & $.81^{* *}$ & 1.00 & \\
Knowledge & $.70^{* *}$ & $.82^{* *}$ & 1.00 \\
Practice & $.71^{* *}$ & $.89^{* *}$ & $.81^{* *}$ \\
\hline
\end{tabular}

\section{Discussion}

Findings of the current study revealed that about half of studied nurses were in the age group of $26-<30$ years followed by $34.2 \%$ in the age group of $21-<26$ years with a mean age of (29.32) years. Concerning total clinical experience $(45.7 \%)$ of the nurses had $1-5$ years of clinical experience, $(37.2 \%)$ had more than 10 years of clinical experience and (17.1\%) had $6-10$ years of clinical experience. With respect to professional educational qualification, it was observed that (12.9\%) of the respondents were having bachelor degree in nursing and $87.1 \%$ of respondents were with diploma in Nursing.

Generally, in nursing education, there is a significant gap between the theory taught in lectures and the realities of clinical practice. Study findings shows that none of the nurses in the study sample had satisfactory total knowledge and practice at the pre-program implementation. Although few of them had satisfactory knowledge regarding some aspect, the majority had unsatisfactory knowledge regarding ureteral stent management, patient's teaching and stent removal which shows that there is a need of educational programmes in order to improve their knowledge level. These results are in line with previous literature and studies [13-16].

The score of total knowledge and practice were significantly increased immediately after the program, and continued to be higher at the follow-up period, this may indicate that, educational programme leads to gain knowledge, and improve practice which might have an impact on improvement of ureteral stent management. This result was supported with Taha A., (2017) who reported that their study sample had significant higher mean total knowledge score post teaching than pre teaching [17]. (First and second hypotheses were supported).
The current study findings illustrates that increasing age and experience of studied nurses have an effect on their knowledge. These findings are supported by some studies $[18,19]$ concluded that the level of nurses experience more than 5 years, and age more than 40 , had better knowledge scores.

As well, education as one of the categorical variables was found to have an effect on total mean knowledge score of the studied sample with a high tendency of who had a bachelor degree to have higher mean total knowledge score than Diploma nurses. This finding reflects an obvious improvement after implementation of the program.

It was found in the current study that there was a strong positive correlation between age, experience, knowledge and practice for studied nurses. This result was in agreement with who found in their study that a positive correlation was found between age, knowledge, experience and practices. [20]. (Third hypothesis was supported).

\section{Conclusion}

The current study shows that none of the nurses in the study sample had satisfactory total knowledge at the preprogram implementation, indicating that the respondents lacked knowledge. However, the score of total knowledge increased immediately after the program, and continued to be higher at the follow-up phase, indicating that the nurses gained knowledge after the teaching program which was implemented. On the other hand, it was observed that there was an association between age, years of experience, and knowledge, and practice of nurses regarding uretral stent management. As well, age, years of experience, and education were found to have an impact on knowledge scores. 


\section{Recommendations}

The following recommendations have been suggested based on the current study findings:

A similar study can be done on a large sample to generalize the findings.

A study can be conducted by including additional demographic variables. Manuals, information booklets and self-instruction module should be developed in areas of uretral stent management.

Nurses should take initiative to improve their knowledge and practices by using online education, virtual learning, booklets, posters, brochures, charts etc.

Posters and simple illustrations about uretral stent management should be available in every surgical department.

\section{References}

[1] Matthias B and Thomas O. (2018): Ureteral stents in urolithiasis. Asian J Urol. 2018 Oct; 5 (4): 274-286.

[2] British Association of Urological Surgeons (2017): Telescopic Insertion and Removal of Stent from the Ureter July 2017, $\begin{array}{lllll}\text { Leaflet } & \text { No: } & 17 / 147 & P & 1-7\end{array}$ http://www.baus.org.uk/_userfiles/pages/files/Patients/Leaflets /Ureteric stent insertion. $\bar{p} d f$.

[3] Yang Y., Tang Y., Bai Y., Wang X., Feng D., Han P. (2018): Preoperative double-J stent placement can improve the stonefree rate for patients undergoing ureteroscopic lithotripsy: a systematic review and meta-analysis. Urolithiasis. Oct; 46 (5): 493-499.

[4] Fröhlich M., Fehr J., Sulser T., Eberli D., Mortezavi A. (2017): Extraction strings for ureteric stents: is there an increased risk for urinary tract infections? Surg Infect (Larchmt) 2017; 18: 936-940. [PubMed] [Google Scholar].

[5] Charles D. Scales, Gregory E. Tasian, Andrew L. Schwaderer, David S. Goldfarb, Robert A. (2016) Urinary Stone Disease: Advancing Knowledge, Patient Care, and Population Health. CJASN July 2016, 11 (7) 1305-1312.

[6] Karen M. Doerscha Elmekreshb G. Luke M Marawan M. (2018) The use of a string with a stent for self-removal following ureteroscopy: A safe practice to remain. Arab Journal of Urology, Volume 16, Issue 4, December 2018, Pages 435-440.

[7] Laura N. Nguyen M, Kim T. Matthew R, and James W. (2015): Development and incorporation of hybrid simulation OSCE into in-training examinations to assess multiple competencies in urologic trainees Can Urol Assoc J. 2015 JanFeb; 9 (1-2): 32-36.

[8] Siska B. (2018): Introducing new technology safely into urological practice. World Journal of Urology April 2018, Volume 36, Issue 4, pp 543-548.
[9] Ben Turney. (2016): Ureteric stent, information for patients. Oxford University Hospitals NHS Foundation. https://www.ouh.nhs.uk/patient-guide/leaflets/default.aspx

[10] Freifeld Y., Goldin D., Khalili L., Friedman B., Boyarsky L., Klein I. (2017) Does the use of ureteral stents with extraction strings increase urinary infection rates? Int Urol Nephrol. 2017; 49: 763-767. [PubMed] [Google Scholar].

[11] Koprowski C., Kim C., Modi P. K., Elsamra S. E. Ureteral stent-associated pain: a review. J Endourol. 2016; 30: 744753. [PubMed] [Google Scholar].

[12] Oliver R., Wells H., Traxer O. (2018): Ureteric stents on extraction strings: a systematic review of literature. Urolithiasis. 2018; 46 (2): 129-136.

[13] Nesbitt A. L. Urinary incontinence: not a typical ureteric stent symptom. Urol Case Rep. 2018; 19: 4-5.

[14] AlkanC, Fatih Y, Faruk O, Metin S, Harun O, Akif E, Bahar Y, Omer S. (2018): Comparison of $4.8 \mathrm{Fr}$ and 6 Fr ureteral stents onstent related symptoms following ureterorenoscopy: A prospective randomized controlled trial. Journal of Medical Sciences (2018) Volume 34, 695-699.

[15] Paul C. Brooks N. Ghareeb G. Tracy C. (2017) Pilot Study to Determine Optimal Stent Duration Following Ureteroscopy: Three versus Seven days. Curr Urol 2017; 11: 97-102.

[16] Nilsun A. and Ayse W. (2017): Ureteral stent infections: a prospective study. Braz J Infect Dis vol. 21 no. 3 Salvador May/June 2017

[17] Taha A., (2017) "Impact of a Designed Teaching Protocol about Nursing Management of Coronary Artery Bypass Grafting on Nurse's Knowledge, Practices and Patient's Outcome." IOSR Journal of Nursing and Health Science (IOSR-JNHS) 6.4: 13-28

[18] Olfat Farouk Thabet (2019)."Effect of Developing and Implementing Nursing Care Standards on outcome of Patients Undergoing Cardiac Catheterization". IOSR Journal of Nursing and Health Science (IOSR-JNHS), vol. 8, no. 01, pp. $42-54$.

[19] Mohammed GT, Mohammed, ZA and Al-Araby, HA. (2016): impact of designed nursing educational protocol on health promotion for patients undergoing coronary artery stent outcome; IOSR Journal of Nursing and Health Science (IOSR-JNHS); Volume 5, Issue 2 Ver. VI, PP 54-63.

[20] Saleh M., Ali J., Afifi W., (2018), Nurses Compliance to Standards of Nursing Care for Hemodialysis Patients: Educational and Training Intervention. IOSR Journal of Nursing and Health Science (IOSR-JNHS) e- ISSN: 23201959. p-ISSN: 2320-1940 Volume 7, Issue 2 Ver. IX PP 48-60 www.iosrjournals.org. 